\title{
PENGEMBANGAN MODUL RADIATOR TRAINER UNTUK MENINGKATKAN HASIL BELAJAR MAHASISWA JURUSAN TEKNIK MESIN UNESA
}

\author{
Sudirman Rizki Ariyanto ${ }^{1}$ I Made Arsana ${ }^{2}$, Riyadlul Ulum ${ }^{3}$ \\ ${ }^{1}$ Program Studi Pendidikan Teknologi dan Kejuruan, Pascasarjana, Universitas Negeri Surabaya; \\ ${ }^{2,3}$ Jurusan Teknik Mesin, Fakultas Teknik, Universitas Negeri Surabaya \\ Email: sudirman.17070895007@mhs.unesa.ac.id ${ }^{1}$
}

ABSTRACT

\begin{abstract}
This study aims to develop modules as a learning media to facilitate the students in their learning of heat transfer. The study also try to obtain an overview of the developed modules' feasibility. This is a development research which aim is to produce a learning module. This module was tested in the Department of Mechanical Engineering at Surabaya State University. Fifteen students were randomly selected as respondents. The stages carried out in the development of this module comprise of the following phases: defining, designing, and the development. Analysis of the data obtained from students' learning outcome after attending the study using the "Radiator Trainer Heat Transfer Module" shows an increasing performance. The post-test proofed that there is an increase in students' marks compared to the pre test outcome. The average of the increment is $93 \%$ of all students.
\end{abstract}

Keywords: radiator, trainer, heat transfer, module, learning outcome

\begin{abstract}
ABSTRAK
Penelitian ini bertujuan menghasilkan perangkat pembelajaran berupa modul yang berguna untuk mempermudah mahasiswa dalam mempelajari ilmu perpindahan panas. Selain itu, kajian ini memperoleh gambaran tentang kelayakan modul yang dikembangkan. Penelitian ini merupakan penelitian pengembangan yang bertujuan untuk menghasilkan sebuah modul pembelajaran. Uji coba modul ini dilakukan di Jurusan Teknik Mesin, Universitas Negeri Surabaya. Responden penelitian sejumlah 15 mahasiswa yang dipilih secara acak. Tahap-tahap yang dilakukan dalam pengembangan modul ini meliputi tahap pendefinisian, tahap perancangan dan tahap pengembangan. Berdasarkan analisis data yang diperoleh hasil belajar mahasiswa setelah mengikuti pembelajaran dengan menggunakan "Modul Perpindahan Panas Radiator Trainer" menjadi lebih meningkat, terbukti dari hasil perbandingan pre-test dan post-test terjadi peningkatan dengan nilai rata-rata sebesar 93\% dari seluruh mahasiswa.
\end{abstract}

Kata kunci: modul perpindahan panas radiator trainer, perpindahan panas, dan hasil belajar

\section{PENDAHULUAN}

Metode pembelajaran merupakan salah satu faktor penting dalam proses pembelajaran. Pada umumnya metode pembelajaran yang sering diterapkan dalam proses pelaksanaan pembelajaran masih menggunakan metode tradisional (metode ceramah). Metode tradisional ini adalah metode pembelajaran yang berpusat pada dosen, sehingga dosen lebih mendominasi dan mahasiswa menjadi pasif (kurang aktif) (Rufii, 2015). Penerapan metode tradisional ini cenderung mengabaikan tingkat mental mahasiswa, sehingga mahasiswa sulit dalam untuk kreatif dan berpartisipasi pada saat proses pembelajaran berlangsung (Khalid, 2012). Metode tradisional memiliki kelebihan tersendiri dalam penerapannya, akan tetapi metode tersebut dianggap tidak cocok untuk generasi saat ini. Dosen dituntut agar semakin kritis dengan menggunakan berbagai ilmu pendidikan dan strategi pengajaran yang dapat digunakan untuk mendorong agar mahasiswa dapat ikut berpartisipasi (Serbessa, 2006).

Menurut Felder (1996), tujuan pendidikan adalah untuk membantu mahasiswa 
dalam upaya membangun keterampilan mereka dalam mempelajari hal yang disukai dan kurang disukai. Mahasiswa memiliki gaya belajar yang berbeda-beda sesuai dengan karakteristik dan keinginan mereka dalam mengambil dan memproses informasi. Proses pengambilan informasi di era yang serba teknologi seperti saat ini dapat dilakukan melalui media online dan juga media cetak seperti buku ataupun berupa modul pembelajaran. Sesuai dengan pendapat Winkel (1991), modul merupakan bahan ajar yang dapat digunakan untuk belajar secara mandiri atau secara individu karena modul berisi tujuan, lembar instruksi, bahan bacaan, kunci jawaban, dan alat evaluasi. Modul dapat digunakan sebagai alternatif bentuk penyajian bahan yang digunakan dalam pembelajaran.

Pendapat lain yang dikemukakan oleh Daryanto (2011) menyatakan bahwa modul adalah salah satu bentuk media pembelajaran dikemas secara utuh dan sistematis, dimana di dalamnya memuat seperangkat pengalaman belajar yang terencana dan didesain secara khusus untuk membantu mahasiswa dalam menguasai tujuan pembelajaran yang spesifik. Dalam belajar keterampilan khusus modul memberi peranan penting, dimana melalui penggunaan modul dosen dapat membantu mahasiswa dalam memberi instruksi secara mandiri. Pembelajaran dengan menggunakan modul menjadi populer karena penerapannya yang konkret dan memiliki prinsip yang cocok untuk kemampuan mahasiswa (Auditor, 2014).

Berdasarkan hasil belajar mahasiswa pada mata kuliah perpindahan panas mahasiswa D3 Teknik Mesin Universitas Negeri Surabaya dikatakan sangat kurang, sebagai gambaran nilai mata kuliah perpindahan panas semester genap 2014-2015 adalah sebagai berikut: dari 21 mahasiswa yang memprogram mata kuliah perpindahan panas tidak ada mahasiswa yang mendapat nilai A (0\%), sebanyak 2 mahasiswa mendapat nilai A- (10\%), 9 mahasiswa mendapat nilai $\mathrm{B}+(43 \%), 10$ mahasiswa mendapat nilai B (48\%) dan 0 mahasiswa untuk nilai B-, C+, C, D dan E (0\%).
Terdapat beberapa faktor yang diprediksi dapat mempengaruhi hasil belajar mahasiswa, diantaranya adalah kemampuan dosen dalam mengembangkan kemampuan mahasiswa, kurangnya respon mahasiswa dalam pelaksanaan pembelajaran (Lee, et all., 2011), belum tersedianya perangkat pembelajaran berupa modul yang dapat digunakan secara dan belum tersedianya kompetensi praktikum dalam silabus mata kuliah perpindahan panas. Di laboratorium perpindahan panas terdapat beberapa perangkat pembelajaran yang digunakan secara khusus untuk mempelajari perpindahan panas konveksi.

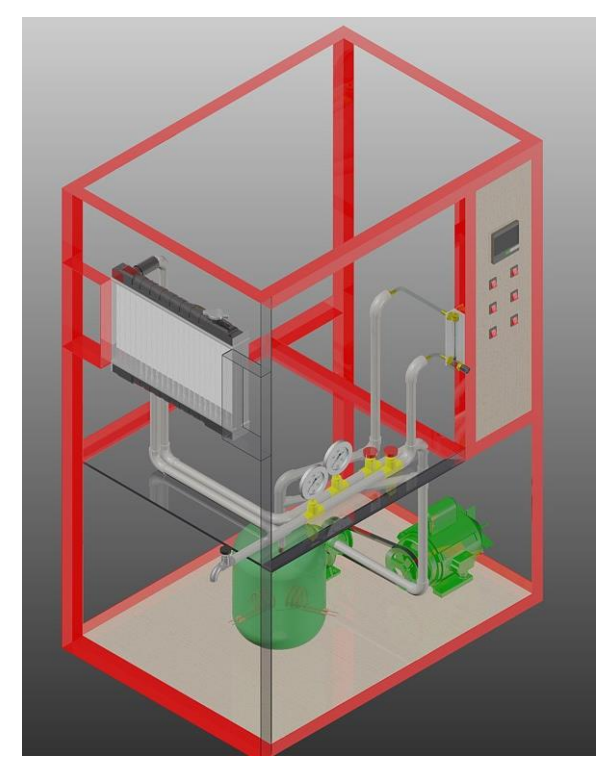

Gambar 1. Radiator Trainer

Sumber: Ahmad dan Arsana (2016)

Menurut Cengel (2003) konveksi merupakan proses perpindahan panas yang terjadi antara permukaan benda padat dengan fluida yang mengalir sebagai media penghantarnya. Ada dua jenis konveksi yang umum kita ketahui yaitu, konveksi paksa konveksi bebas (Holman, 2010). Radiator Trainer merupakan salah media pembelajaran yang digunakan untuk mempelajari konveksi paksa. Sesuai dengan namanya, Radiator Trainer adalah sebuah media pembelajaran yang digunakan untuk mendemonstrasikan perpindahan panas konveksi yang terjadi pada radiator. Radiator merupakan alat yang 
berfungsi sebagai media perantara yang menggunakan fluida cair dan udara dalam penyerapan panas dari mesin yang kemudian dibuang melalui sirip-sirip pendingin (kuppan, 2000).

Radiator trainer digunakan untuk mendemonstrasikan perpindahan konveksi yang terjadi pada permukaan radiator. Radiator trainer juga dapat digunakan untuk mengetahui pengaruh fluida terhadap kapasitas penukar panas dengan cara memvariasi (merubah) temperatur fluida masuk. Berikut gambar Radiator Trainer yang digunakan sebagai media dalam proses pembelajaran.

Radiator Trainer dapat mengetahui kapasitas penukar panas suatu radiator. Menurut Arsana (2015), kapasitas penukar panas adalah kemampuan suatu alat penukar panas (radiator) dalam memindahkan panas secara total atau keseluruhan. Secara teoretis banyak pengetahuan yang bisa kita dapatkan bila Radiator Trainer ini bisa diterapkan dalam proses pembelajaran. Namun, dalam penggunaannya alat tersebut masih dianggap kurang efektif jika diterapkan. Selain itu, belum tersedianya perangkat pembelajaran yang berupa modul menjadi salah satu faktor yang menjadi kendala bagi dosen dan mahasiswa pada saat diterapkan. Banyak referensi dan sumber belajar yang dapat dijadikan acuan, akan tetapi referensi dan sumber belajar yang secara khusus dan spesifik membahas tentang perpindahan panas konveksi paksa masih belum ada. Oleh karena itu belum adanya modul dapat disebutkan sebagai salah satu kendala dalam pelaksanaan pembelajaran yang mengakibatkan respon mahasiswa belum maksimal.

Keberhasilan penggunaan modul dapat dilihat dari hasil penelitian sebelumnya. Mirkouei (2016), menyimpulkan bahwa penggunaan modul dapat membawa banyak manfaat seperti modul digunakan sebagai sarana strategi pembelajaran secara efektif dan modul sebagai sarana penarik minat mahasiswa dalam memahami bahan ajar. Modul membuat mahasiswa menjadi lebih aktif. Hal ini dianggap lebih efektif daripada metode tradisional yang hanya terpaku pada tugas tertulis. Pre-test dan post-test sebagai parameter pemahaman mahasiswa. Dimana hasil pre-test digunakan sebagai patokan sebelum penggunaan modul dan post-test untuk mengindikasi level atau hasil dari pembelajaran setelah menggunakan modul.

Fajarini et al. (2016), mengungkapkan bahwa penggunaan modul dapat memberikan dampak positif, diantaranya yaitu memberikan kesempatan bagi mahasiswa agar dapat belajar serta meningkatkan kemampuan dalam hal mengamati dan memahami masalah di lingkungan sekitarnya baik di bidang sosial maupun ekonomi. Modul dapat menimbulkan rasa ingin tahu yang kuat bagi mahasiswa dan menimbulkan sikap disiplin. Tidak hanya manfaat bagi individu penerapan modul juga dapat memberikan manfaat secara berkelompok.

Sudarwati (2013) menjelaskan bahwa modul dapat dianalogikan sebagai pembimbing yang dapat digunakan kapan saja dan dimana saja. Modul dapat meringankan beban kerja dosen dan banyak manfaat yang akan didapat mahasiswa dari penggunaan modul, diantaranya: mahasiswa menjadi lebih aktif mencari tahu, mahasiswa lebih termotivasi untuk mengajukan pertanyaan, dan dapat membuat mahasiswa lebih berprestasi dengan memanfaatkan pengetahuan mereka dengan baik.

Merujuk dari beberapa hasil penelitian terdahulu maka dapat diketahui bahwa mahasiswa dapat lebih efektif dalam belajar jika didukung dengan adanya perangkat pembelajaran berupa modul (Devesh, 2014). Oleh karena itu, dengan adanya "Modul Perpindahan Panas Konveksi Radiator Trainer" diharapkan mampu untuk membuat mahasiswa belajar secara mandiri baik di dalam maupun di luar kampus.

\section{METODE}

Penelitian ini termasuk dalam penelitian pengembangan. Model pengembangan yang 
digunakan yaitu sesuai dengan alur pengembangan modul yang dikembangkan oleh Thiagarajan, dkk yaitu model 4-D. Subjek penelitian ini adalah mahasiswa program studi D3 Teknik Mesin Universitas Negeri Surabaya angkatan 2015 yang sedang memprogram mata kuliah perpindahan panas. Responden penelitian sejumlah 15 mahasiswa yang dipilih secara acak.
Alur pengembangan dalam penelitian ini berdasarkan pengembangan model 4-D. Namun, dalam penelitian pengembangan ini dilakukan modifikasi sehingga tahapan yang dilaksanakan hanya tahap define, design, dan develop, untuk langkah disseminate akan dilakukan oleh peneliti selanjutnya, sebagaimana yang ditunjukkan dalam Gambar 2.

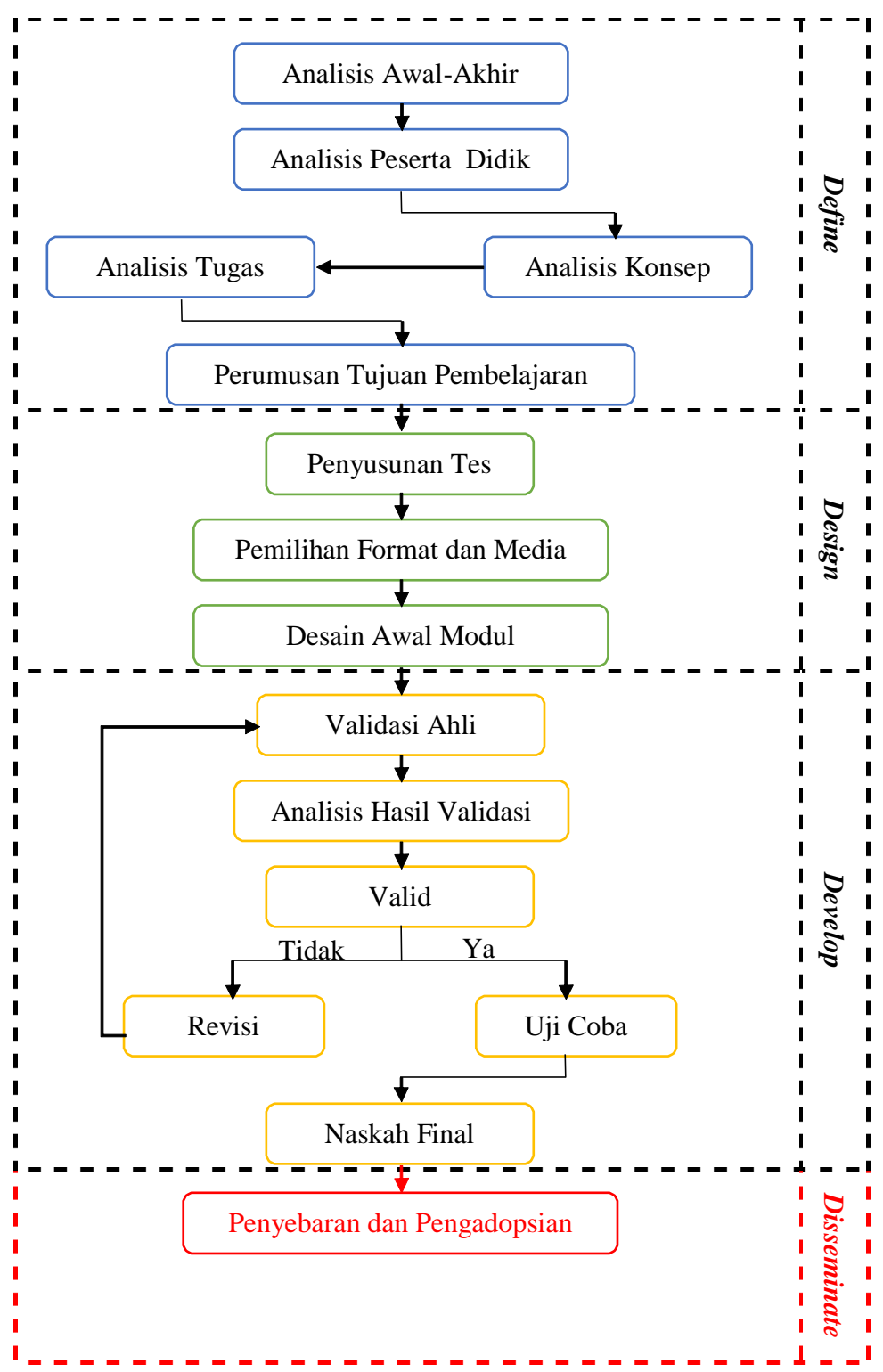

Gambar 2. Alur Pengembangan Modul Thiagarajan (4-D)

Tahap pertama adalah define. Pada tahap ini analisis awal dilakukan dengan studi pustaka dan pada bagian akhir analisis dilakukan dengan cara survei lapangan. Studi pustaka dilakukan dengan mengkaji kurikulum yang ada berlaku dan survei lapangan dilakukan untuk mengetahui kondisi sesungguhnya yang terjadi selama mengikuti proses pembelajaran. Berdasarkan hasil analisis dan persyaratan yang berlaku, maka indikator pencapaian dirumuskan 
dengan kompetensi dasar dan hasil belajar yang ingin dicapai. Rincian indikator pencapaian bertujuan untuk merumuskan tujuan pembelajaran spesifik, yang kemudian akan dijadikan dasar dalam penyusunan materi uji (Mappalotteng, et al., 2015).

Tahap kedua adalah design. Tahap ini dilakukan untuk menghasilkan rancangan awal perangkat pembelajaran berupa modul dengan

Tahap ketiga yaitu develop. Tahap ini bertujuan untuk menghasilkan bentuk akhir dari perangkat pembelajaran setelah melalui proses validasi yang dilakukan oleh validator. Langkah selanjutnya adalah melakukan uji coba terbatas dengan jumlah responden sebanyak 15 orang mahasiswa yang dipilih secara acak. Kegiatan ini dilakukan untuk mengetahui seberapa efektif perangkat pembelajaran yang telah dikembangkan ketika diterapkan dalam proses pembelajaran (Zuhri, 2015).

Teknik analisis data dilakukan dengan menggunakan teknik analisis deskriptif, yaitu dengan menganalisis data kuantitatif yang diperoleh dari hasil belajar siswa. Menurut Arikunto (2006:207), data kuantitatif berwujud angka-angka hasil perhitungan atau pengukuran dapat diproses dengan cara dijumlah, dibandingkan dengan jumlah yang diharapkan dan diperoleh persentase.

Perolehan hasil belajar mahasiswa (posttest) merupakan akumulasi dari hasil belajar afektif, kognitif dan psikomotor dengan persentase afektif $10 \%$, kognitif $20 \%$ dan psikomotor 70\% (Fransiska, 2013:38).

Kriteria Ketuntasan Minimal (KKM) yang digunakan yaitu 75. Apabila nilai akhir yang diperoleh $>75$ maka dikategorikan tuntas, sedangkan jika $<75$ dikategorikan tidak tuntas. Dari hasil rekapitulasi, nilai akhir (post-test) dibandingkan dengan nilai sebelum mahasiswa menerapkan modul pembelajaran (pre-test). Dari hasil perbandingan tersebut maka kita dapat mengetahui persentase peningkatan hasil belajar mahasiswa antara sebelum dan sesudah menerapkan modul pembelajaran. menggunakan Radiator Trainer sebagai media penukar panas. Selain itu, pada tahap ini juga akan dihasilkan materi uji yang berfungsi untuk mengukur kemampuan berfikir mahasiswa baik dari segi kognitif maupun psikomotor. Pada tahap ini terdapat 3 langkah yang harus dilakukan, antara lain penyusunan tes, pemilihan format dan media dan desain awal modul (Rasiman, 2014).

\section{HASIL DAN PEMBAHASAN}

Hasil belajar mahasiswa dibandingkan dari hasil pre-test dan post-test. Pre-test diujikan pada mahasiswa sebelum menggunakan modul dan post-test diujikan setelah menggunakan modul dengan standar nilai kelulusan $>75$. Penilaian post-test dibagi dalam 3 aspek yaitu ranah afektif, ranah kognitif, dan ranah psikomotor.

Dalam ranah afektif terdapat 2 sikap yang dinilai yaitu sikap religius dan sikap sosial, dimana pada sikap sosial ada dua indikator penilaian yang meliputi tanggung jawab dan proaktif. Pada ranah kognitif terdapat 2 kriteria penilaian meliputi tes formatif dan evaluasi pembelajaran, pada tes formatif terdapat 4 indikator yaitu tes formatif 1 hingga tes formatif 4 . Sedangkan penilaian dari ranah psikomotor didapatkan dari keterampilan pada saat melakukan praktikum dan hasil laporan praktikum yang berupa tugas, dimana tugas tersebut terdiri dari tugas $\mathrm{kb} 2$ hingga tugas $\mathrm{kb}$ 4.

Adapun hasil pre-test ditunjukkan pada Tabel 1, hasil penilaian aspek afektif ditunjukkan pada Tabel 2, hasil penilaian aspek kognitif ditunjukkan pada Tabel 3, hasil penilaian aspek psikomotor ditunjukkan pada Tabel 4 dan hasil penilaian akhir (post-test) ditunjukkan pada Tabel 5. 
Tabel 1. Data Hasil Pre-test

\begin{tabular}{|c|c|c|c|c|}
\hline No & NIM & Responden & Nilai & Keterangan \\
\hline 1. & 035 & Responden 1 & 55 & Belum Tuntas \\
\hline 2. & 036 & Responden 2 & 50 & Belum Tuntas \\
\hline 3. & 038 & Responden 3 & 47,5 & Belum Tuntas \\
\hline 4. & 040 & Responden 4 & 35 & Belum Tuntas \\
\hline 5. & 042 & Responden 5 & 45 & Belum Tuntas \\
\hline 6. & 043 & Responden 6 & 55 & Belum Tuntas \\
\hline 7. & 045 & Responden 7 & 50 & Belum Tuntas \\
\hline 8. & 048 & Responden 8 & 60 & Belum Tuntas \\
\hline 9. & 049 & Responden 9 & 42 & Belum Tuntas \\
\hline 10. & 050 & Responden 10 & 52,5 & Belum Tuntas \\
\hline 11. & 053 & Responden 11 & 40 & Belum Tuntas \\
\hline 12. & 055 & Responden 12 & 47,5 & Belum Tuntas \\
\hline 13. & 060 & Responden 13 & 47,5 & Belum Tuntas \\
\hline 14. & 061 & Responden 14 & 52,5 & Belum Tuntas \\
\hline 15. & 062 & Responden 15 & 52,5 & Belum Tuntas \\
\hline
\end{tabular}

Tabel 2. Data Hasil Belajar Ranah Afektif

\begin{tabular}{|c|c|c|c|c|c|c|}
\hline \multirow{2}{*}{ No } & \multirow{2}{*}{ NIM } & \multirow{2}{*}{ Responden } & \multicolumn{3}{|c|}{ Aspek } & \multirow{2}{*}{ Rata-rata } \\
\hline & & & Religius & Tanggung Jawab & Proaktif & \\
\hline 1. & 035 & Responden 1 & 100 & 100 & 100 & 100 \\
\hline 2. & 036 & Responden 2 & 100 & 100 & 100 & 100 \\
\hline 3. & 038 & Responden 3 & 93,75 & 100 & 100 & 97,92 \\
\hline 4. & 040 & Responden 4 & 81,25 & 93,75 & 100 & 91,67 \\
\hline 5. & 042 & Responden 5 & 81,25 & 93,75 & 100 & 91,67 \\
\hline 6. & 043 & Responden 6 & 81,25 & 100 & 100 & 93,75 \\
\hline 7. & 045 & Responden 7 & 93,75 & 87,5 & 100 & 93,75 \\
\hline 8. & 048 & Responden 8 & 100 & 75 & 100 & 91,67 \\
\hline 9. & 049 & Responden 9 & 81,25 & 87,5 & 100 & 89,58 \\
\hline 10. & 050 & Responden 10 & 81,25 & 87,5 & 100 & 89,58 \\
\hline 11. & 053 & Responden 11 & 87,5 & 93,75 & 100 & 93,75 \\
\hline 12. & 055 & Responden 12 & 93,75 & 87,5 & 81,25 & 87,50 \\
\hline 13. & 060 & Responden 13 & 100 & 87,5 & 100 & 95,83 \\
\hline 14. & 061 & Responden 14 & 93,75 & 93,75 & 100 & 95,83 \\
\hline 15. & 062 & Responden 15 & 87,5 & 93,75 & 100 & 93,75 \\
\hline
\end{tabular}


Tabel 3. Data Hasil Belajar Ranah Kognitif

\begin{tabular}{cccccc}
\hline No & NIM & Responden & Tes Formatif & Evaluasi Pembelajaran & Rata-rata \\
\hline 1. & 035 & Responden 1 & 97,5 & 100 & 98,75 \\
2. & 036 & Responden 2 & 100 & 100 & 100 \\
3. & 038 & Responden 3 & 100 & 97,5 & 98,75 \\
4. & 040 & Responden 4 & 98,25 & 90 & 94,13 \\
5. & 042 & Responden 5 & 92,5 & 92,5 & 92,50 \\
6. & 043 & Responden 6 & 98,75 & 95 & 96,88 \\
7. & 045 & Responden 7 & 97 & 90 & 93,50 \\
8. & 048 & Responden 8 & 66,25 & 90 & 78,13 \\
9. & 049 & Responden 9 & 100 & 92,5 & 96,25 \\
10. & 050 & Responden 10 & 95 & 95 & 95 \\
11. & 053 & Responden 11 & 100 & 92,5 & 96,25 \\
12. & 055 & Responden 12 & 100 & 92,5 & 96,25 \\
13. & 060 & Responden 13 & 98,75 & 90 & 94,38 \\
14. & 061 & Responden 14 & 98,75 & 87,5 & 93,13 \\
15. & 062 & Responden 15 & 85,25 & 82,5 & 83,88 \\
\hline
\end{tabular}

Tabel 4. Data Hasil Belajar Ranah Psikomotor

\begin{tabular}{cclccc}
\hline No & NIM & Responden & Tugas KB & Keterampilan & Rata-rata \\
\hline 1. & 035 & Responden 1 & 96,67 & 95 & 95,83 \\
2. & 036 & Responden 2 & 97,50 & 95 & 96,25 \\
3. & 038 & Responden 3 & 99,17 & 95 & 97,08 \\
4. & 040 & Responden 4 & 94,00 & 89 & 91,5 \\
5. & 042 & Responden 5 & 93,17 & 82 & 87,58 \\
6. & 043 & Responden 6 & 99,17 & 95 & 97,08 \\
7. & 045 & Responden 7 & 100 & 85 & 92,5 \\
8. & 048 & Responden 8 & 95,33 & 80 & 87,67 \\
9. & 049 & Responden 9 & 97,50 & 90 & 93,75 \\
10. & 050 & Responden 10 & 92,83 & 85 & 88,92 \\
11. & 053 & Responden 11 & 97,50 & 85 & 91,25 \\
12. & 055 & Responden 12 & 92 & 90 & 91 \\
13. & 060 & Responden 13 & 88,83 & 95 & 91,92 \\
14. & 061 & Responden 14 & 92,33 & 89 & 90,67 \\
15. & 062 & Responden 15 & 91,50 & 88 & 89,75 \\
\hline
\end{tabular}

Tabel 5. Data Hasil Belajar Penilaian Akhir (Post-test)

\begin{tabular}{lccccccc}
\hline No & NIM & Responden & $\begin{array}{c}\text { Afektif } \\
(10 \%)\end{array}$ & $\begin{array}{c}\text { Kognitif } \\
(20 \%)\end{array}$ & $\begin{array}{c}\text { Psikomotor } \\
(70 \%)\end{array}$ & N.A & Keterangan \\
\hline 1. & 035 & Responden 1 & 10 & 19,75 & 67,08 & 96,83 & Tuntas \\
2. & 036 & Responden 2 & 10 & 20 & 67,38 & 97,38 & Tuntas \\
3. & 038 & Responden 3 & 9,79 & 19,75 & 67,96 & 97,50 & Tuntas \\
4. & 040 & Responden 4 & 9,17 & 18,83 & 64,05 & 92,04 & Tuntas \\
5. & 042 & Responden 5 & 9,17 & 18,5 & 61,31 & 88,98 & Tuntas \\
\hline
\end{tabular}




\begin{tabular}{cccccccc}
\hline No & NIM & Responden & $\begin{array}{c}\text { Afektif } \\
(10 \%)\end{array}$ & $\begin{array}{c}\text { Kognitif } \\
(20 \%)\end{array}$ & $\begin{array}{c}\text { Psikomotor } \\
(70 \%)\end{array}$ & N.A & Keterangan \\
\hline 6. & 043 & Responden 6 & 9,38 & 19,38 & 67,96 & 96,71 & Tuntas \\
7. & 045 & Responden 7 & 9,38 & 18,7 & 64,75 & 92,83 & Tuntas \\
8. & 048 & Responden 8 & 9,17 & 15,63 & 61,37 & 86,16 & Tuntas \\
9. & 049 & Responden 9 & 8,96 & 19,25 & 65,63 & 93,83 & Tuntas \\
10. & 050 & Responden 10 & 8,96 & 19 & 62,24 & 90,20 & Tuntas \\
11. & 053 & Responden 11 & 9,38 & 19,25 & 63,88 & 92,50 & Tuntas \\
12. & 055 & Responden 12 & 8,75 & 19,25 & 63,70 & 91,70 & Tuntas \\
13. & 060 & Responden 13 & 9,58 & 18,88 & 64,34 & 92,80 & Tuntas \\
14. & 061 & Responden 14 & 9,58 & 18,63 & 63,47 & 91,68 & Tuntas \\
15. & 062 & Responden 15 & 9,38 & 16,78 & 62,83 & 88,98 & Tuntas \\
\hline
\end{tabular}

Perhitungan hasil post-test (N.A):

$$
\begin{aligned}
\text { N.A } & =(\text { Afektif } \times 10 \%)+(\text { Kognitif } \times 20 \%)+(\text { Psikomotor } x 70 \%) \\
& =(100 \times 10 \%)+(98,75 \times 20 \%)+(95,83 \times 70 \%) \\
& =96,83
\end{aligned}
$$

Berdasarkan hasil belajar mahasiswa sebelum menggunakan modul (pre-test) didapatkan hasil penilaian yang masih dibawah KKM (kriteria kelulusan minimal) $>75$. Hal tersebut sesuai dengan Tabel 1, dari 15 mahasiswa belum ada satupun yang masuk dalam kategori tuntas. Namun, bila dibandingkan dengan hasil belajar akhir setelah menggunakan modul (post-test) terdapat peningkatan hasil belajar yang sanga signifikan. Hal tersebut dapat dilihat pada Gambar 3 berikut ini.

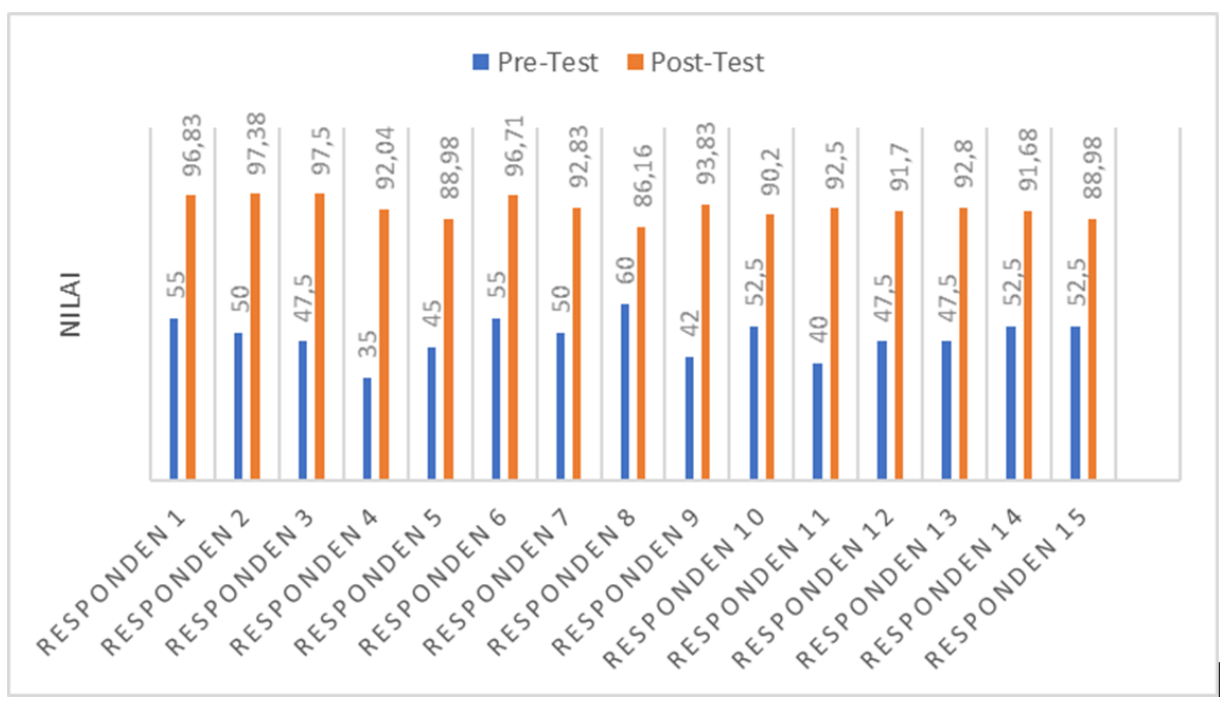

Gambar 3. Perbandingan Hasil Belajar Pre-test dan Post-test

Sesuai Gambar 3 dapat dilihat bahwa terjadi peningkatan hasil belajar pada semua mahasiswa. Jika dirata-rata terjadi peningkatan sebesar 93\% pada setiap mahasiswa. Adanya peningkatan nilai rata-rata hasil belajar mahasiswa setelah menggunakan modul 
menunjukkan bahwa dengan menerapkan modul dapat meningkatkan hasil belajar mahasiswa. Hal ini membuktikan bahwa indikator keberhasilan dalam penelitian ini telah tercapai dan modul yang dikembangkan masuk dalam kategori layak untuk digunakan sebagai media pembelajaran.

\section{SIMPULAN}

Kesimpulan yang diperoleh dari hasil dan pendalaman penelitian adalah pengingkatan hasil belajar setelah menggunakan "Modul Perpindahan Panas Radiator Trainer" serta dibuktikan dari hasil perbandingan pre-test dan post-test terjadi peningkatan dengan nilai ratarata sebesar 93\% dari seluruh mahasiswa.

\section{DAFTAR RUJUKAN}

Abdullah, N. L., Hanafiah, M. H., \& Hashim, N. A. (2013). Developing Creative Teaching Module: Business Simulation in Teaching Strategic Management. International Education Studies: Vol. 6, No. 6, 95-107.

Adams, W. K, \& Wieman, C. L. (2010). Development and Validation of Instruments to Measure Learning of Expert-Like Thingking. International Journal of Science Education.

Arikunto, Suharsimi. (2006). Prosedur Penelitian Suatu Pendekatan Praktik, (Jakarta: Asdi Mahasatya, 2006).

Arsana, I. Made. (2016). Modelling Of The Single Staggered Wire And Tube Heat Exchanger. International Journal of Applied Engineering Research, Vol. 11, No 8, 5591-5599.

Auditor, E. \& Naval, D. J. (2014). Development and Validation of Tenth Grade Physics Modules Based on Selected Least Mastered Competencies. International Journal of Education and Research, Vol 2, No. 12 December 2014, 145-152.
Ahmad, F., dan Arsana, I., M. 2015. Perencanaan Sistem Aliran Fluida Pada Rancang Bangun Alat Penguji Kapasitas Radiator. Tugas Akhir Tidak dipublikasikan. Surabaya: Universitas Negeri Surabaya.

Boone, H. N., \& Boone, D. A. (2012). Analyzing Likert Data. Journal of Extension, Vol. 50, No. 2, April 2012.

Cengel, Yunus A., (2003). Heat Transfer: A Practical Approach. $2^{\text {nd }}$ Edition. McGraw-Hill. New York.

Daryanto. (2013). Menyusun Modul. Malang: Gava Media

Devesh, S., \& Nasseri, D. A. 2014. Effectiveness of Mathematics Module in Foundation Programme in Majan College. International Journal of Emerging Engineering Researh and Technology, Vol 2, Issue 1, 1-7.

Fajarini, A., Soetjipto B. E., \& Hanuwaran, F. (2016). Developing A Social Studies Module by Using Problem Based Learning (PBL) With Scaffolding for the Seventh Grade Students in A Junior High School in Malang, Indonesia. IOSR Journal of Research \& Method in Education (IOSR-JRME), Vol. 6, Ver. III, 63-69.

Felder, R.M. (1996). "Matters of style." ASEE Prism, 6(4), 18-23.

Holman, J. P. (2010). Heat Transfer. 10 Edition. McGraw-Hill. USA.

Khalid, A. \& Azeem, M. (2012). Constructivist vs Traditional: Effective Instructional Approach in Teacher Education. International Journal of Humanities and Social Science, Vol. 2, No. 5, March 2012, 170-177.

Kuppan, T. (2000). Heat Exchanger Handbook. Marcel Dekker, Inc. New York.

Lee, Y. J., Chao, C. H. \& Chen, C. Y. (2011). The influences of interest in learning and learning hours on learning outcomes of vocational college students in Taiwan: 
using a teacher's instructional attitude as the moderator. Global Journal of Engineering Education, Vol. 13, No.3, 140-153.

Mappalotteng, A. M., Nur, H., and Kanan, F. (2015). The Development of Programmable logic controller tutorial in the form of industrial-based learning material in vocational high schools. International Journal of Engineering and Science, Vol. 5, Issue 5, 49-58.

Mirkouei, A., Bhinge, R., McCoy, C., Haapala, K.R and Dornfeld, D. A. (2016). A Pedagogical Module Framework to Improve Scaffolded Active Learning in Manufacturing Engineering Education. 44th Proceedings of the North American Manufacturing, Vol. 5, 1128-1142

Rasiman \& Pramasdyahsari, A. S. (2014). Development of Mathematics Learning Media E- Comic Based on Flip Book Maker to Increase the Critical Thinking Skill and Character of Junior High School Students. International Journal of Education and Research, Vol 2, No. 11, November 2014, 535-544.

Rufii, R. (2015). Developing Module on Constructivist Learning Strategies to Promote Students' Independence and Performance. International Journal of Education, Vol. 7, No. 1, 18-28.

Serbessa, D. D. Tension between Traditional and Modern Teaching-Learning Approaches in Ethiopian Primary
Schools. Journal of International Cooperation in Education, Vol 9, No. 1, 123-140.

Sudarwati, N., (2013). Developing an Integrated Module on Entrepreneurship to Improve Ability in Making Business Plans. International Journal of Business, Humanities and Technology, Vol. 3, No. 5, May 2013, 109-135.

Sugiyono. (2011). Metode Penelitian Kuantitatif, Kualitatif Dan $R \& D$. Bandung: Alfabeta.

Thiagarajan, S, Semmel, D. S., and Semmel, M. I. (1974). Instructional Development for Training Teachers of Exceptional Children. Leadership Training Institute/Special Education, Minesota: University of Minesota, Minneapolis.

Tim. 2004. Pemeliharaan/Servis Sistem Pendingin dan KomponenKomponennya. Yogyakarta: Universitas Negeri Yogyakarta

Zuhri, M. S. (2015). Designing of Tool for Teaching Based on Computer Interactive Learning and Computer Assisted Learning to Improve the Skill of Learner. Proceeding International Conference on Vocational Education and Electrical Engineering (ICVEE) 2015, PPG Building UNESA, November $18^{\text {th }} 2015$, 95-99.

Winkel. (1991). Psikologi Pengajaran. Jakarta: Penerbit PT Grasindo. 